\title{
Intergenerational effects on individual charitable donation: an innovative study on philanthropy in China
}

\author{
Yongjiao Yang ${ }^{1 *}$ (D), Yuting Shi ${ }^{2}$ and Dong Zhang ${ }^{3}$
}

\author{
* Correspondence: \\ yangyongjiao11@outlook.com \\ ${ }^{1}$ School of Public Affairs, Chongqing \\ University, No.174 Shazhengjie, \\ Shapingba, Chongqing 400044, \\ China \\ Full list of author information is \\ available at the end of the article
}

\begin{abstract}
The family, which is the basic unit of Chinese society, serves as the micro foundation of individual charitable behavior. This study examines the intergenerational effects on individual charitable donations in China based on China's unique social structure, traditional culture, and philanthropic history. The study identifies the mutual influence of children's charitable donation and parent's charitable donation through both downward and upward intergenerational transmission. The effect of upward transmission is stronger than that of downward inheritance, especially among families with children born in the 1980s and 1990s. The findings reflect the "familyoriented" culture of Chinese society and highlight the necessity and urgency of developing a charitable donation theory rooted in Chinese experiences.
\end{abstract}

Keywords: Charitable donation, Downward intergenerational transmission, Upward intergenerational reverse transmission, Indigenous studies

\section{Introduction}

\section{For a theory of Chinese charitable donation}

Charitable donation refers to donating tangible or intangible assets to charitable organizations or beneficiaries voluntarily and gratuitously. Both Chinese and international sociology academics have conducted decades of research on individual charitable donation and have explored the connotation, occurrence, type, participation, and sustainability of charitable donation. Both internal factors and external factors influence donations. Internal factors refer mainly to donation motivations caused by demand, which include self-interest, altruism, and reciprocity. The studies of self-interest motivation focus primarily on obtaining wealth and social reputation, whereas the studies of altruistic motivation focus on altruistic obligation and social responsibility, and the studies of reciprocal motivation are conducted from the perspective that both the donor and the beneficiary benefit from donation behavior (Vesterlund 2006).

External factors are manifested in many aspects and include institutional factors, organizational factors, and environmental factors. From the perspective of institutions, a tax exemption policy promotes Pareto improvement, advances the total utility of

(c) The Author(s). 2020 Open Access This article is licensed under a Creative Commons Attribution 4.0 International License, which permits use, sharing, adaptation, distribution and reproduction in any medium or format, as long as you give appropriate credit to the original author(s) and the source, provide a link to the Creative Commons licence, and indicate if changes were made. The images or other third party material in this article are included in the article's Creative Commons licence, unless indicated otherwise in a credit line to the material. If material is not included in the article's Creative Commons licence and your intended use is not permitted by statutory regulation or exceeds the permitted use, you will need to obtain permission directly from the copyright holder. To view a copy of this licence, visit http://creativecommons.org/licenses/by/4.0/. 
donation, and plays an incentive role (Hochman and Rodgers 1977). From the perspective of the organizational process, charitable donation generates incentives, such as satisfactory ability and credibility of charity organizations and high-quality charitable activities and projects (Zhao 2011). From the social environment perspective, a charitable donation is embedded in the social network significantly impacted by social capital, mobilization, and peer pressure (Meer 2011; Hu and Shen 2013; Bi et al. 2010). Moreover, individual characteristics, such as socioeconomic status, gender, and education level, are frequently discussed as factors for donation in academia (Bénabou and Tirole 2006; Bekkers and De Graaf 2006; Andreoni and Vesterlund 2001).

However, the role and function of the family in the individual charitable donation are rarely discussed. The research orientation is related to the basic structure of Western society. According to (Fei 1998), in the "group pattern" (tuanti geju) of the modern Western society, the relationships among people are similar to "a bundle of firewood"; in each group, even if there are differences between "subgroups" in terms of grouping and hierarchy, the relationships between the internal members are equal, and the boundaries between units in the group structure are clear (Ma 2007). This characteristic of the social structure and the operating rules are closely related to religion (Christianity). In Western society, religion and God are the symbols of groups. Two vital concepts are derived from these symbols: each individual is equal before God, and God is fair to each individual. The relationship between groups and individuals symbolizes the relationship between God and believers in which God is a judge with rewards and punishments, a guard of justice, and an omnipotent protector (Fei 1998). As one of the group units, the family is no more important than other group units, such as the state or church. According to (Liang 2005), when Western society turned to large group life from Christianity, the family became less important, and clan became more divisive. The cultural tradition of philanthropy originated from and developed in this social structure reflects the deep-rooted concepts of individual orientation, mutual aid culture, and religion-orientated philanthropy (Han and Zheng 2014). As a result, the perspective of Western academic research on charitable behavior often focuses on individual characteristics, charitable organizations, and religious impacts and seldom adopts the family perspective.

In China, research on individual charitable donation began recently, and most relevant studies utilize previously proposed theories based on the Western experience. According to Nan Lin (1986), a common problem prevailed in Chinese academia: the "unreflective transplantation" of Western theories to analyze the Chinese experience. Scholars do not substantially adjust the Western research framework to the particularity of Chinese contexts and seldom develop new theoretical explanations based on the differences between the Chinese experience and Western theories. From the perspective of epistemology or methodology, "the validity of knowledge in crossing contexts" (Wang 2017:18) becomes inevitable when the concepts and perspectives of Western sociological theories are utilized to examine the reality in the Chinese social context. To overcome the "non-acclimatization" between the theoretical perspective and the research object or application context, we must adopt a "localization of sociology" approach. In this study, the Chinese social structure and cultural characteristics, which differ from those of the Western society, must be considered when analyzing the main factors or driving forces of individual charitable behavior of Chinese people in order to 
develop a theory of Chinese charitable donation. Through examining the influence of the institutional environment on individual giving in China, studies have identified the "Chinese characteristics" of philanthropy (Bi et al. 2010). By exploring individual charitable donations from the family perspective, this study further promotes the construction and development of a philanthropy theory based on the Chinese experience.

\section{"Familism" and philanthropy in China}

The social structure significantly influences people's behavior. In the study of individual charitable donation, the social structure in which the behavior is embedded cannot be ignored. The formation of the Chinese social structure is substantially influenced by Confucian traditional culture. The kernel of Confucian ethics is to regard the family as the perfect embodiment of social relations and the responsibility to the family as superior to all other responsibilities, such as responsibilities and obligations to the emperor, the God(s), or any other secular or religious authority (Fukuyama 2001). This emphasis on the "familism" is reflected in the following: First, the premise for individuals to enter social life is to participate in different moral life in the family that, in turn, form a moral standard. Second, individuals' significance and value in social life must be realized through their contributions to the family (Wen 2014). By scrutinizing China's familism from a historical perspective, it is reasonable to conclude that the long-lasting family institution is a basic defense system, which helps individuals fight against the risky and fickle environment. The many small-scale family businesses in Chinese society also demonstrate Chinese people's dependence on their families and family members.

In line with the tradition of Confucian culture and the moral system, China's social structure is identified as a "differential mode of association" (cha xu ge ju), which differs from the "group pattern" of Western society (Fei 1998). The connotation of the "differential mode of association" can be summarized as behavioral interaction patterns among social members being differentiated by the distance and proximity of the relationship. A network of social relations is formed sequentially by close and distant relationships centered on the individual (Zhang 2010). This social network model emphasizes the significance of consanguinity, the relativity of public-private and groupself relationships, the self-centered ethical values, and the etiquette order of "using traditional interpersonal relations and ethics to maintain social order" (Yan 2006). In contrast to the Western society dominated by "groups," in China, "family" (which includes the family and the clan) plays an important role next to "the individual" in the structure of the "differential mode of association" (Yu 2003; Ma 2007) and even surpasses the meaning of the individual according to various scholars (Chen 2011). (Yan 2006) suggested that the two characters of "cha" (distance) and " $x u$ " (rank) in the "differential mode of association" reflect the "human relations" (ren lun) that are emphasized by Confucianism, which is an ethical and social order system that was established prior to the existence of the individual. In the practice of human relations in Confucianism, the family is the major arena. The filial piety of "father and son" in the five ethics (wu lun) constitutes the starting point of these practices (Shen 2007). Whether it is "five ethics" or "ten ethics," the relationships between people differ according to distance and hierarchy. 
Although contemporary Chinese society had undergone tremendous changes since Xiaotong Fei proposed the "differential mode of association," traditional Confucian culture still influences all aspects of social life imperceptibly. Despite 40 years of reform and opening-up and social transformation, the inertia of China's long history is too powerful to be neglected (Ma 2007). Familial metaphors, such as "within the four seas all men are brothers" and "one family in the world," once served as grand political goals in Confucianism and reflected the concept of "familism" (Shen 2007). Furthermore, although China has been committed to building the family as a "social unit" that is suitable for industrialized and market-oriented systems, the traditional functions of families and their influence on family members remain strong since the social welfare systems are not well-established for supporting such "modern" families (Yao 2012).

The logic of "familism" has substantially influenced philanthropy in China. First, from the perspective of the intrinsic value of individual philanthropy, "benevolence" that is based on "familism" involves "the difference of love," which is distinct from the value of "universal love" that is emphasized by Western Christian tradition (Huang 2008). Therefore, philanthropy's cultural tradition demonstrates the characteristics of family (clan) orientation, official leadership, and relative underdevelopment of grassroots charity (Han and Zheng 2014). Influenced by "familism," China's philanthropy is characterized by closeness; namely, the donors and the beneficiaries could be familiar with each other. The narrow scope of the beneficiaries is the embodiment of the acquaintance culture, which is inconsistent with the spirit of "stranger ethics" of modern philanthropy, which has the characteristics of sociality, openness, and universality (Yang 2009). It substantially affects the passion of the general public for participation in charitable donation, which is demonstrated by the ranking of China's charitable giving level in the world. According to the World Donation Index 2015, China's individual giving level ranks the second-lowest among the 145 countries and regions surveyed; the index of money donation ranks 136 and the index of volunteering time 144 (Charity Aid Foundation 2015).

Although "familism" in Chinese society has hindered the development of modern philanthropy, the above perspective regarding the role of the family in philanthropy is merely one side of the coin. The structural characteristics of Chinese society render it difficult for individuals to act free of the influence of family, and the roles of family in the performance of charitable behavior and the cultivation of charitable culture can be multifaceted. From the perspective of the spread and diffusion of charitable behaviors and ideas, due to an individual's dependence on family, their decision-making regarding charitable behavior will be constantly influenced by their families. According to Weber (1995), Chinese people's trust is a special type of trust: They only trust people who have a personal relationship (kinship or quasi kinship) rather than trusting strangers. The family is the primary group in which family members share close relationships and frequent interactions, and the behavioral impact is immediate. Therefore, due to China's social structure, the cultivation of philanthropy depends heavily on the family relationship, and the charitable behavior also depends substantially on the behaviors and attitudes of other members of the family. Compared with external stimulation, the mobilization from the family, and the transmission and diffusion of charitable values inside the family may be effective long-term strategies for promoting the development of philanthropy in China. 
In China, the family has an aggregated effect on individual philanthropy since the family can effectively collect the scattered philanthropic resources of family members and participate in philanthropy in an overall form. Although the family is the initial place for the cultivation of children's altruistic spirit and social responsibility and the "incubator" for charity awareness and behavior in both Chinese and Western societies, a charitable donation in China is often initiated by the family as an economic entity, and donation decisions are made primarily by the husband and the wife together (Zhu and Liu 2017). In this sense, interactions between family members regarding their philanthropic behaviors and ideas are common. Based on the characteristics of China's social structure, an incentive strategy in which philanthropy is centered on the family and radiated out would be effective. To improve the effect of this incentive strategy of philanthropy in China, we must understand the mutual influence of family members' charitable behaviors better to utilize the endogenous motivation of individual charitable behavior and explore the positive social function of "familism."

Based on the above analysis, we argue that the characteristics of China's social structure and the role of the family in encouraging individual donation require more emphasis and proactive exploration when discussing individual charitable donations. The transmission of philanthropy culture among family members may have a remarkable effect on individual charitable donations. Since the reform and opening-up, the environment of philanthropy in China has been constantly improved. Examination of the mechanism of the family's influence on individual philanthropy and clarification of the special significance of the family in the construction of philanthropy theory and in stimulating internal motivation for charitable behavior in China are of substantial importance. This study will discuss the influence of the family on individual charitable donations from the perspective of family relationships. There are three basic relationships in Chinese families-conjugal, sibling, and parental relationships. Among them, the vertical parent-child relationship is the most important, representing the main aspect of family relationships and occupies a more important position than the horizontal husband-wife and sibling relationships (Pan and Lin 1992). Even with the trend of small and nuclear families, the conjugal relationship in contemporary Chinese families still does not occupy the central position of the parent-child relationship in the family (Ma et al. 2011). Therefore, this study will explore the influence of intergenerational relationships on individual charitable donations.

\section{Literature review: intergenerational effect on charitable donation}

Previous research and limitations

Although the value of "familism" has a profound impact on Chinese philanthropy, the research on the impact of the family on individual philanthropy in China lags behind that in the West due to the late start of Chinese philanthropy research. Previous studies are based mainly on the Western social structure and social environment.

According to relevant studies, family philanthropy has a downward intergenerational transmission effect, namely, parents' charitable behavior, donation preferences, and participation in voluntary service positively impact children (Lily Family School of Philanthropy 2016). Hodgkinson and Weitzman's study (Hodgkinson and Weitzman 1992) demonstrates that in American society if parents participate in voluntary work, their 
children are twice as likely to participate in voluntary work. In addition, Wilhelm et al. (2008) used the Panel Study of Income Dynamics (PSID) data in the US to explore whether adult children inherit their parents' generosity. The study shows a strong positive correlation between parents and their adult children in religious donation participation, while there is a positive but weaker correlation in secular donation.

In academia, the downward intergenerational transmission is typically defined as the phenomenon in which parents' abilities, concepts, behaviors, and social status are transferred to their children (Chi and Xin 2013). Intergenerational transmission embodies the intergenerational relationship. The intergenerational relationship can encompass not only the relationships between parents and children and between grandparents and grandchildren in the family but also the relationships between the old generation, the middle-aged generation, and the young generation in the society (Deng and $\mathrm{Xu} 2001$ ). Although these studies find that charitable behavior can be passed from generation to generation, this transmission mechanism requires further explanation. From the perspective of sociology, the downward intergenerational transmission of charitable donations can be explored via two approaches.

The first approach emphasizes that parents influence children's donation behavior through the role model effect (Eisenberg and Fabes 1998). This explanation focuses on the process of socialization in which children can learn charitable behavior through "social learning" (Moen et al. 1997). Although socialization occurs in schools, churches, and among peers, families are often regarded as the most important entity for the socialization of values (Bengtson 1975). Role models influence generosity and altruism (Mustillo et al. 2004). As role models, parents can encourage their children's prosocial behavior through verbal persuasion, other-oriented guidance, and personality approval based on empathy (Eisenberg and Fabes 1998).

The second approach emphasizes the transmission of social and economic resources that are related to a charitable donation. According to the theory of intergenerational transmission of social status, the motivation for charitable participation is randomly distributed, while the capacity for charitable participation is not. Parents play a critical role in providing resources for charitable participation (Featherman and Hauser 1978). Parents may not transfer values and beliefs to their children, but they provide their children the possibility of obtaining social, cultural, and economic resources and status in a broader social structure (Moen et al. 1997). If parents transfer resources to the next generation, children are more capable of involvement in activities that require these resources, such as charitable donation (Acock 1984; Glass et al. 1986). This also increases children's opportunity to participate in charitable donation and helping others (Eisenberg 1990).

Although previous studies have explored the influence of the intergenerational family relationship on individual charitable behavior, there are two main limitations.

First, most studies on the intergenerational transmission of charity behavior are conducted in Western countries. Relevant studies in the Chinese context are in a marginal position, and survey data and quantitative analyses are not abundant. In Chinese society, the core position of the family and the interaction patterns among family members under the influence of Confucian culture may have a more complex intergenerational impact on the charitable donation: Influenced by the Confucian concept of "benevolent father, filial son," the thoughts and behaviors of individuals are substantially inherited; 
however, in Chinese society, charitable behavior may reflect a reverse intergenerational effect; namely, the younger generation may profoundly influence the older generation. This is deeply branded with Chinese characteristics. With the transformation from a traditional society to modern society, the renewal cycle of knowledge and technology is unceasingly shortened, and the phenomenon of "cultural feedback" or "reverse socialization" is striking. The authority of the elder in the family has been challenged, while the position and decision-making power of children in the family have increased (Zhou 2000). Especially for China's modern philanthropy, since this transformation accelerated in the 21 st century, it is the post-80s generation and the younger generation who are substantially affected; hence, the younger generation could affect the older generation. This merits further discussion. An in-depth discussion of this phenomenon would not only help enrich the relevant theories of philanthropy research but also have substantial theoretical and practical significance for the expansion of the relevant studies on China's social change.

Second, the previous studies focus mainly on parents' influence on the donation behavior of under-age children and neglect the impact of intergenerational transmission in adulthood. Behind this research tendency is the implicit hypothesis of a Western family relationship, namely, adult children enjoy relatively high degrees of independence and self-sufficiency, and the interactions among family members are more of an exchange than of authority. However, in Chinese families, the power structure is influenced by Confucian culture and ethics. Although the intergenerational relationship is becoming more equal and democratic with the changes of the era, the reciprocal culture of filial piety is deeply rooted in the individual's subjective consciousness. It provides individuals in a risk society with a sense of cognitive security, belonging, and purpose of existence (Shi 2016).

Moreover, in contemporary China, marriage often closely connects the two families. After the marriage of adult children, the two families have a close relationship and rely on each other in child-rearing and economic life. The 2010 census data show that China's contemporary family composition is characterized by a decreased number of nuclear families and an increased number of stem families, and the number of multimarriage families remains stable (Wang 2013). After marriage, adult children are influenced by their parents-in-law in terms of ideas and behaviors, and the adult children influence the parents-in-law in turn. Therefore, the inheritance and reverse influence of adult children's charitable behavior in the family merits further discussion.

\section{Cultural feedback and charitable donation}

In the patterns of "inheritance" and "socialization," the direction of cultural transmission is unidirectional over a substantial period of human civilization developmentfrom the parents' generation to the child's generation in the family and from top to bottom in the society. This concept of "father is the model of the son" in these two patterns is regarded as the basic rule of cultural heritage in all civilized societies (Zhou 2000). However, in modern times, especially since the "information technology revolution" at the end of the twentieth century and the beginning of the twenty-first century, the drastic transformation of human society and the rapid development of civilization have resulted in a fractured cultural phenomenon, namely, a "generation gap" between 
the two generations that live under the same roof, which has even evolved into intergenerational conflict.

In contrast to the traditional and unidirectional "parent-child inheritance" mode, in modern society (especially after the Second World War), the generation of the parents gradually loses their absolute power of socialization, while the children obtain unprecedented "feedback" ability (Zhou 2000). In Western society, Mead first summarized the process of "reverse socialization" from the younger generation to the older generation through the concept of the "post-figurative culture" (Mead 1987). In China's transformation, especially in the 40 years of the reform and opening-up, the speed and intensity of the social and cultural changes at the level of materials are unprecedented. In this era of substantial changes, the young Chinese generation plays the role of a "tide player," bypassing knowledge and culture to their living predecessors and, thus, becoming the "initiator" of the new cultural transmission mode (Zhou 2000). In response to this phenomenon, (Zhou 1988:23) proposed the concept of "cultural feedback," which was defined as "the process of extensive cultural absorption of the older generation from the younger generation in the era of rapid cultural change."

Does the transmission of modern philanthropy culture in contemporary Chinese society reflect the characteristics of "cultural feedback"? We argue that charitable behavior can not only be "passed on" to children but also "fed back" to parents, which is often realized through "reverse socialization." "Reverse socialization" refers to transferring culture and ideas from the younger generation to the older generation. With society's transformation from traditional to modern, the renewal cycle of knowledge and technology is shortened, and social change is intensified. The young generation exhibits a high degree of adaptability to modern society, and their ability to accept and master the knowledge of modern society is far superior to that of their parents. The generation of parents becomes the recipient of education. The absolute authority of parents in traditional families has been severely challenged (Tian 2009). In the family life and cultural inheritance between parents and children, the differences in the ability of the two generations to accept and adapt to new things render the phenomenon of cultural feedback more distinct (Zhou 2000). Meanwhile, under the influence of family planning and other policies, China's family structure is miniaturized, and the downward parent-child relationship has received unprecedented attention (Yang 2011), which also increases the possibility of back-feeding charitable behavior. The children's rights to speech and decision-making in the family have been strengthened, laying the foundation for influencing the parents' charitable attitudes and behaviors.

Moreover, the intergenerational feedback of charitable behavior is affected by the change of the philanthropic environment. Since the founding of the People's Republic of China, there have been three millstones of national philanthropy: the revival of China's philanthropy, which began in 1981; the rise of philanthropy began in 2008; and the legalization of China's philanthropy, which began in 2016. As a virtue, the charity has undergone three thousand years of inheritance and development. After the founding of the People's Republic of China, philanthropy in modern times was interrupted (1949-1981); after the reform and opening-up, philanthropy in China was revived (1981-1994), and after 14 years of development (1994-2008), starting in 2008, under the influence of the Olympic Games and the Wenchuan earthquake, "nationwide philanthropy" flourished, thereby opening the path of transformation from modern 
philanthropy to contemporary philanthropy (Zhou and Lin 2014). In 2016, the implementation of the Charity Law symbolized that China's philanthropy entered the era of legalization.

The philanthropic environment in China began to improve in the 1980s and significantly advanced in 2008. The environment for participation in philanthropy is optimized, the opportunities are increasing, and the protection of rights and interests is strengthened. Influenced by these reflexive factors, young and capable individuals are more likely to participate in a charitable donation. Among them, the post-80s and post-90s generations are the groups that are most positively affected and are more likely to participate in charitable donation since the favorable philanthropic environment helps this group shape awareness of philanthropy and cultivate different attitudes toward philanthropy starting in childhood. Meanwhile, the post-60s and post-70s generations, which experienced the stagnation of philanthropy in China, are easily influenced by their children, who are more open-minded and independent, in terms of philanthropic ideas and attitudes, thereby resulting in the occurrence of reverse influence.

In summary, we argue that there is an intergenerational effect in an individual charitable donation. In the family, parents and children influence each other's philanthropic consciousness and charitable behaviors through different approaches (see Fig. 1). The parents' downward transmission to the children and the upward feedback from the children to the parents are intertwined, thereby leading to a two-way impact.

Therefore, to further the construction of a theory of philanthropy that is rooted in China, we should attach importance to the vital role of the family as the donor in promoting philanthropy in China, extend the main research object in the field of philanthropy from the "individual" to the "individual in the family," regard the whole family as the mobilization object and fully consider the characteristics and interests of the family. To address the limitations of previous studies, this study will examine the twoway intergenerational effect on charitable donation in the context of China based on the 2014 China Labor-force Dynamic Survey. It will identify the characteristics of

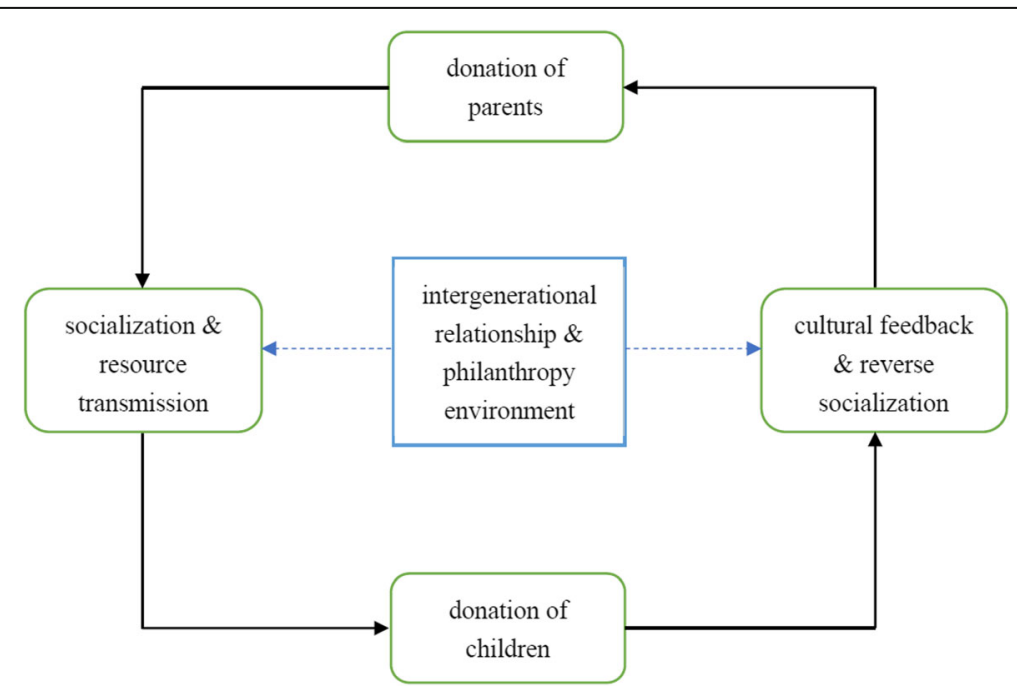

Fig. 1 Diagram of the intergenerational influence on charitable donation 
intergenerational inheritance and feedback of charitable donation in contemporary Chinese society.

\section{Research methods}

Data

The data used in this study are collected from the 2014 China Labor-force Dynamic Survey (CLDS2014), which was conducted by Sun Yat-Sen University. The random samples of CLDS cover 29 provinces and regions (which exclude Hong Kong, Macao, Taiwan, Tibet, and Hainan). The survey adopts multistage clustering, stratified, probability proportionate to size (PPS) sampling methods. CLDS2014 collected a sample of 14,226 families and 23,594 individuals. The respondents to the CLDS family questionnaire were all living with their families, which satisfied the requirements of this study. In a family, the members who live together are more likely to have intensive interaction and communication. Their charitable behavior is more likely to have immediate, longterm, and stable effects on other members. Family members who are not living together are less likely to affect one another, which is not conducive to observing the intergenerational effect of charitable behavior. In addition, as a type of behavior, a charitable donation is more alterable than social and economic status, which may be difficult to transmit among family members with limited interaction and spatial segregation. We observe only the family members who are above 18 years old due to juveniles' limited abilities and opportunities for participation in the charitable donation and due to their generally weak position in the power structure of the family. This facilitates the analysis of the intergenerational impact on charitable behavior and the observation of the role of intergenerational transmission in children's charitable behaviors in adulthood.

To analyze the interaction of charitable behavior between parents and children, we must first identify the one-to-one relationship between parents and children. Two major national surveys that are related to the research topic of this study have been conducted-the China Family Panel Studies (CFPS) and the China Labor-force Dynamic Survey (CLDS). Although CFPS surveyed the overall donations of families as a whole, and the relationships between family members, data on individual family members' donations were not collected. The donation behaviors collected in CLDS can be associated with specific family members, but it only captures the relationships between the questionnaire respondents and their family members. We cannot portray the exact relationship between any two family members from the CLDS data. However, we can indirectly capture all family members' relationships through the relationships between the questionnaire respondents and their family members. This method is not flawless since the relationships among individual family members are difficult to accurately capture when the number of family members is too large. This study generates a sample of parent-child intergenerational relationships in the family according to the following steps.

The first step is to regarding the family questionnaire respondents as the parents and their children (which include sons, daughters, daughters-in-law, and sons-in-law) as the generation of children to generate the "parent-children" data (father_son_1). The second step is to locate, based on the data of father_son_1, the spouses of the family questionnaire respondents. The children of the family questionnaire respondents are also 
the children of their spouses. The data of father_son_2 is generated with the spouse as the parent and their children as the child generation. The third step is to locate the parents (which include the fathers, mothers, fathers-in-law, and mothers-in-law) of the family questionnaire respondents. The data of father_son_3 is generated by the respondents as children and their parents as the parent generation. The fourth step is to locate, based on the data of father_son_3, the IDs of the spouses of the family questionnaire respondents and incorporate them into the data of father_son_3. The parents (which include the fathers, mothers, fathers-in-law, and mothers-in-law) of the respondents are also the parents of their spouses. The data of father_son_4 is generated by the family questionnaire respondents as children and their parents as the parent generation. The fifth step is to combine the data of father_son_1, father_son_2, father_ son_3, and father_son_4 to obtain the relational data of father_son. Finally, according to the respondents' IDs to individual questionnaires, the IDs of the parents, the IDs of the children, demographic variables, and donation data at the individual level are combined. The pair data of parents and children who have responded to individual questionnaires are retained, while the pairs in which the children are younger than 18 years old are deleted. All pair data are then combined with the family data to include relevant variables at the family level. After this process, 6120 pairs of parent-child relational data are obtained.

\section{Variables and analysis method}

As emphasized above, this study focuses on charitable donation. The dependent variables are "whether the parents participated in a charitable donation (last year)" and "whether the children participated in a charitable donation (last year)." This study only considers children and parents who are living together. The parents include mothers, fathers, and parents-in-law; the children include sons, daughters, sons-in-law, and daughters-in-law.

This study also considers common factors that affect charitable donation as control variables. Previous studies show that (1) the higher the individual income level is, the larger the donation resources are, and the more inclined people are to participate in charitable donation (Liu and Lu 2013); (2) the more educated individuals are, the more likely they are to participate in charitable donation (Bekkers and De Graaf 2006); (3) women are more inclined to participate in charitable donation (Andreoni and Vesterlund 2001); (4) age tends to be positively related to the capacity and inclination for charitable donation (Wang and Graddy 2008); (5) religious people are more interested in charitable activities (Bekkers and Wiepking 2010); (6) danwei have special effects on donation since individuals in danwei are often mobilized or forced to participate in donation (Bi et al. 2010); (7) mobilization from Party organizations is often an important factor for individual participation in donation, and the participation rate of Party members in charitable donation is often higher (Hu and Shen 2013); (8) compared with families with multiple children, the parents of the only child are more likely to have donation resources; and (9) family characteristics, such as the family's support for, participation in, and preferences for charitable activities, also impact the donation behaviors of family members. Therefore, the control variables of this study include the following: (1) whether the individuals are members of danwei; (2) the 
logarithm of annual income; (3) age; (4) gender; (5) years of education; (6) whether the individuals are religious believers; (7) party member affiliation with the Communist Party and other political parties; (8) number of children; and (9) whether the individuals have donated in the name of the family. Table 1 presents the descriptive statistics of the variables.

Since there is a potential reciprocal relationship between parents' donation and children's donation, this study uses a non-recursive model to analyze the intergenerational effects of donation (Paxton et al. 2016:2). In this model, we use a two-stage binary logit model to conduct the estimation.

$$
\begin{aligned}
& y_{1}=\ln \left(\frac{P\left(y_{1}=1\right)}{1-P\left(y_{1}=1\right)}\right)=\beta_{1} y_{2}+\gamma \boldsymbol{X}+\varepsilon_{1} \\
& y_{2}=\ln \left(\frac{P\left(y_{2}=1\right)}{1-P\left(y_{2}=1\right)}\right)=\beta_{2} y_{1}+\boldsymbol{\theta} \boldsymbol{X}+\varepsilon_{2}
\end{aligned}
$$

In these formulae, $\mathrm{y}_{1}$ is the $\log$ odds of parents' donation, and $\mathrm{y}_{2}$ is the $\log$ odds of children's donation. There is a linear relationship between the dependent and

\begin{tabular}{|c|c|c|c|c|}
\hline \multirow[t]{2}{*}{ Variables } & \multicolumn{2}{|c|}{ Parents $(N=6120)$} & \multicolumn{2}{|c|}{ Children $(N=6120)$} \\
\hline & $N$ & mean/percentage & $N$ & mean/percentage \\
\hline Have donated & & $100 \%$ & & $100 \%$ \\
\hline Yes (1) & 351 & $5.74 \%$ & 324 & $5.29 \%$ \\
\hline No $(0)$ & 5769 & $94.26 \%$ & 5796 & $94.71 \%$ \\
\hline Income in 2013 (10,000 yuan) & & $2.87(S D=11.70)$ & & $3.03(\mathrm{SD}=5.07)$ \\
\hline Years of education(years) & & $7.03(S D=4.18)$ & & $11.00(S D=3.57)$ \\
\hline Age(years) & & $53.88(S D=7.94)$ & & $27.78(S D=7.09)$ \\
\hline Gender & & $100 \%$ & & $100 \%$ \\
\hline Male (1) & 2784 & $45.49 \%$ & 3141 & $51.32 \%$ \\
\hline Female (0) & 3336 & $54.51 \%$ & 2979 & $48.68 \%$ \\
\hline Member of danwei & & $100 \%$ & & $100 \%$ \\
\hline Yes (1) & 703 & $11.49 \%$ & 575 & $9.40 \%$ \\
\hline No (0) & 5417 & $88.51 \%$ & 5545 & $90.60 \%$ \\
\hline Religious believer & & $100 \%$ & & $100 \%$ \\
\hline Yes (1) & 852 & $13.92 \%$ & 754 & $12.32 \%$ \\
\hline No $(0)$ & 5268 & $86.08 \%$ & 5366 & $87.68 \%$ \\
\hline Political affiliation & & $100 \%$ & & $100 \%$ \\
\hline Party member (1) & 451 & $7.37 \%$ & 354 & $5.78 \%$ \\
\hline Nonparty member (0) & 5669 & $92.63 \%$ & 5766 & $94.22 \%$ \\
\hline Have only one child & & $100 \%$ & & \\
\hline Yes (1) & 1328 & $21.70 \%$ & & \\
\hline No $(0)$ & 4792 & $78.30 \%$ & & \\
\hline Have donated in the name of the family & & $100 \%$ & & $100 \%$ \\
\hline Yes (1) & 400 & $6.54 \%$ & 400 & $6.54 \%$ \\
\hline No $(0)$ & 5720 & $93.46 \%$ & 5720 & $93.46 \%$ \\
\hline
\end{tabular}

Table 1 Descriptive analysis of variables $(N=6120)$ 
independent variables in the model. The exponential transform of the value of the independent variable in the model generates the magnitude of change in the dependent variable's odds value-the odds ratio. In the non-recursive model with a binary dependent variable that is used in this study, we initially run a model to estimate the parents' donation $y_{1}$ while regarding children's donation $y_{2}$ as the independent variable. Next, when running the second binary logit model of the children's donations, the fitted value of the first model-the endogenous independent variable $\mathrm{y}_{1}$ (parents' donation)-is used to obtain the final parameter of the complete model (Shah et al. 2002). Figure 2 presents the non-recursive model (the error terms $\varepsilon 1$ and $\varepsilon 2$ are not shown). Most of the independent variables in this model are characteristics of parents and children, which are exogenous to the dependent variables. The inclusion of these variables is based on careful consideration of relevant theories and literature, facilitating our estimation and identification of this non-recursive model (Paxton et al. 2016:24). The statistical analysis software that is used in this study is $\mathrm{R}$.

\section{Analysis results \\ Model estimation}

The non-recursive model results in Fig. 3 demonstrate that the generations of parents and children influence each other in terms of donation participation in a family with children aged 18 and above. Moreover, the influence of children on their parents is significantly stronger than that of parents on their children. The results demonstrate a satisfactory fit of the model (see Table 2). The model indicates that the parents' donation participation is affected by the Party member affiliation, danwei membership, level of education, religious beliefs, age, and gender and is significantly influenced by the child's donation participation $(p<0.001)$. Party members or danwei members are more

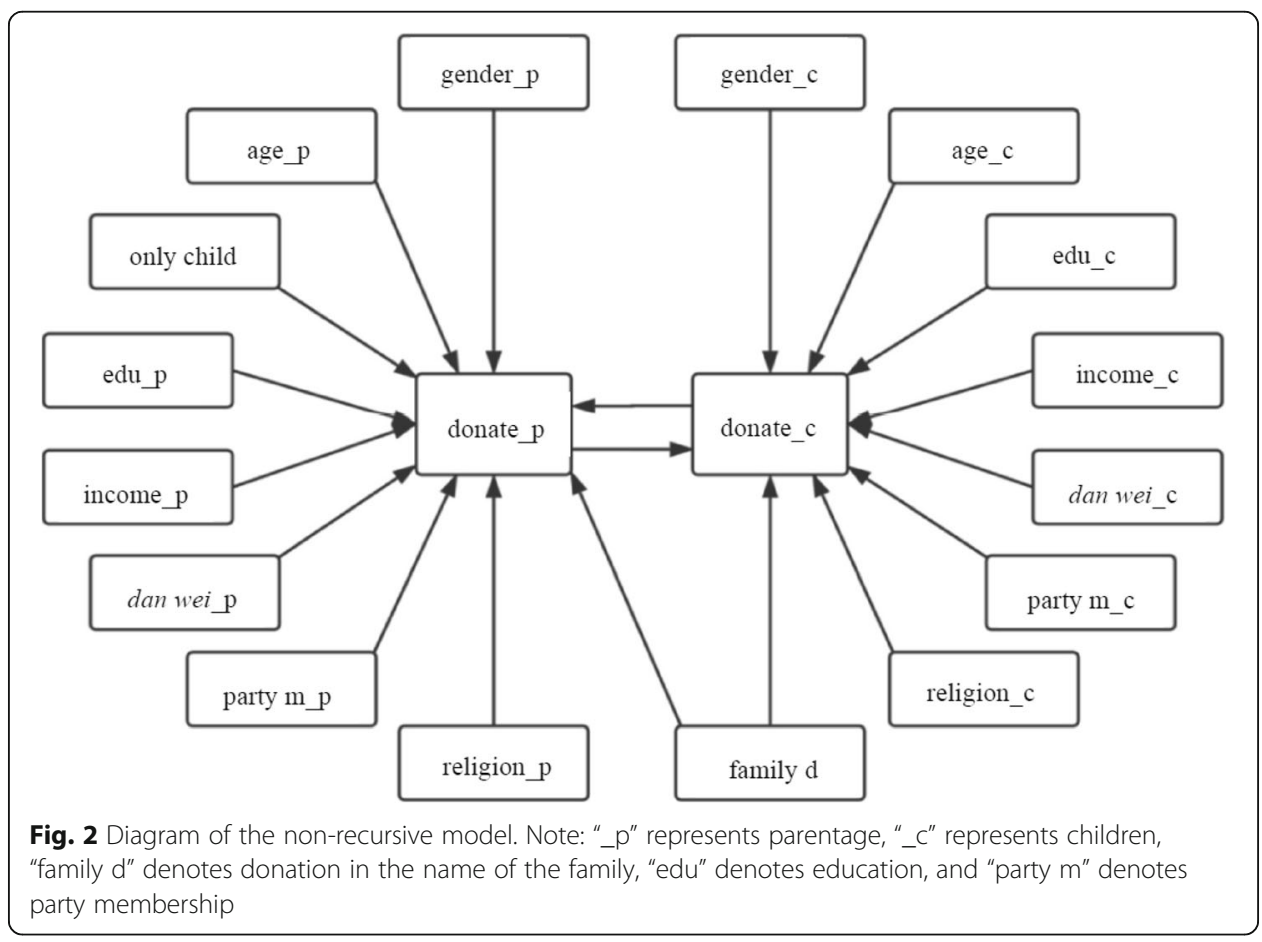




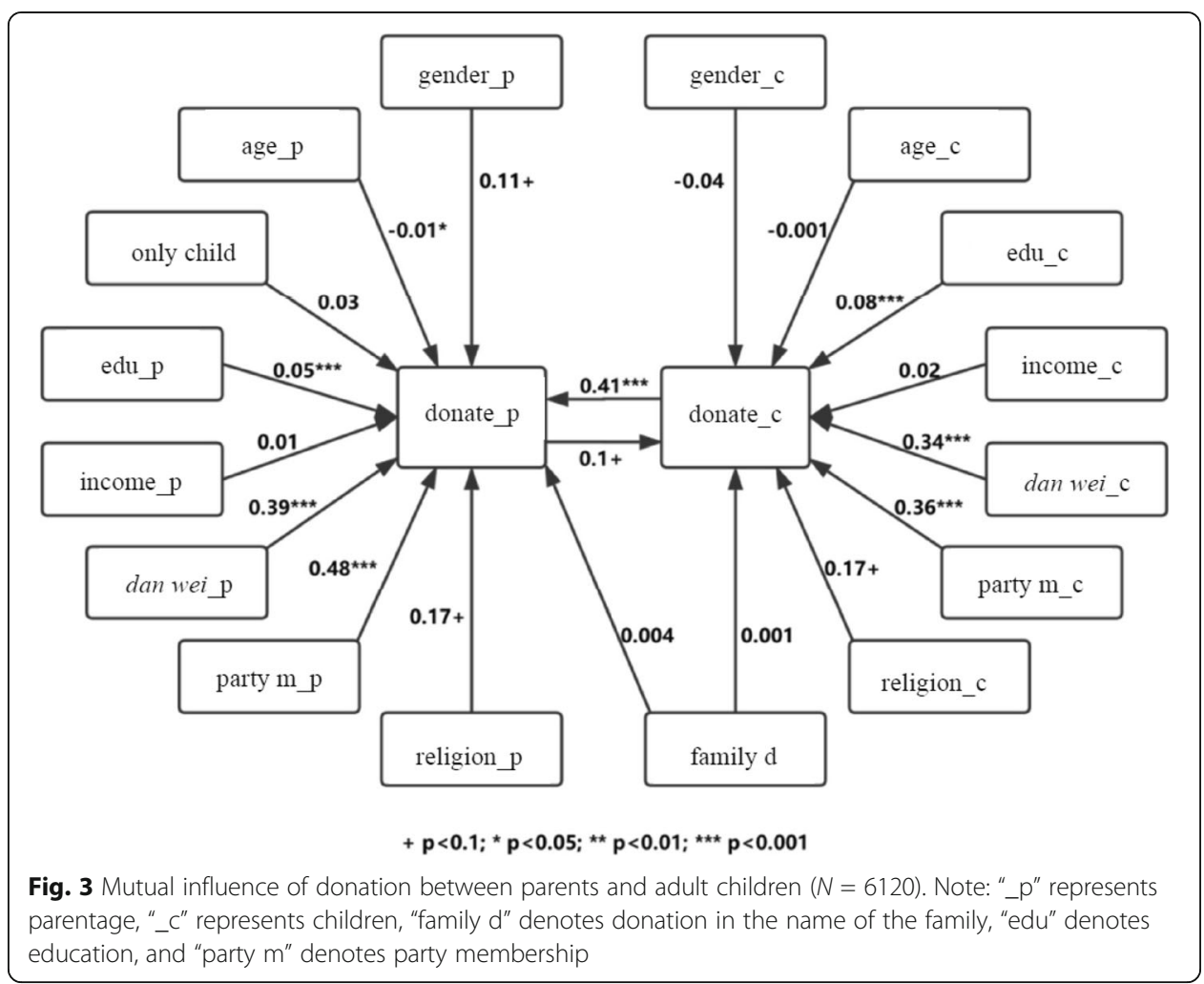

inclined to participate in donation, reflecting the institutional characteristics of philanthropy in China. Meanwhile, children's influence on their parents' donation participation embodies the characteristics of China's social structure. Although the children's donation participation is also affected by the parents' donation participation, the effect is not as strong as Party member affiliation, danwei membership, and education level. The children's donation participation is also affected by religious beliefs. These factors affect both children's and parents' donations.

Table 2 Goodness of fit indices of the models

\begin{tabular}{|c|c|c|c|}
\hline & $\begin{array}{l}\text { Total sample }(N \\
=6120)\end{array}$ & $\begin{array}{l}\text { With children aged } 18- \\
34(N=5079)\end{array}$ & $\begin{array}{l}\text { Robustness test }(N \\
=2730)\end{array}$ \\
\hline \multicolumn{4}{|l|}{ Chi-square $\left(x^{2}\right)$} \\
\hline$x^{2}$ & $27.232(p=0.018)$ & $21.054(p=0.100)$ & $14.515(p=0.412)$ \\
\hline Degrees of freedom & 14 & 14 & 14 \\
\hline \multicolumn{4}{|l|}{ Absolute fit indices } \\
\hline $\begin{array}{l}\text { Root-mean-square error of } \\
\text { approximation (RMSEA) }\end{array}$ & 0.012 & 0.010 & 0.004 \\
\hline $90 \%$ confidence interval of RMSEA & $(0.005,0.019)$ & $(0.001,0.018)$ & $(0.000,0.019)$ \\
\hline $\begin{array}{l}\text { Standardized root-mean-square re- } \\
\text { sidual (SRMR) }\end{array}$ & 0.052 & 0.018 & 0.061 \\
\hline Normed $x^{2}$ & 1.945 & 1.504 & 1.037 \\
\hline \multicolumn{4}{|l|}{ Incremental fit indices } \\
\hline Tucker-Lewis index (TLI) & 0.938 & 0.965 & 0.994 \\
\hline Comparative fit index (CFI) & 0.974 & 0.985 & 0.998 \\
\hline
\end{tabular}


For families with children aged 18-34, the influence of the children on the donation behavior of their parents remains very strong and statistically significant $(p<0.001)$ (see Fig. 4). However, the influence of the parents' donation participation on the children's donation participation becomes insignificant. The variables that significantly affect children's donation participation are Party member affiliation, danwei membership, and education level. The donation participation of the parents is influenced not only by children's donation participation but also by the party member affiliation, danwei membership, level of education, religious beliefs, and gender. The results demonstrate a satisfactory fit and validity of the model (see Table 2). The analysis results demonstrate that, in terms of donation participation, the influence of children on their parents is stronger than that of parents on their children, and this difference in strength is larger for the families with children born after the 1980s.

\section{Robustness test}

Since pairs of internal relationships in the same family could have similarities, the above analysis results might be affected by bias. Therefore, this study reconstitutes a new sample by randomly selecting only one pair of relationships from families with multiple pairs of relationships and evaluates the robustness of the analysis results that are presented above. The sample generation steps are as follows: First, the sample is divided into 10 data sets according to the number of family relationship pairs (the minimum is one parent-child pair and the maximum is ten pairs per family). Second, the relationship pairs in each family are sorted, and sequence numbers $1,2,3 \ldots, n$ ( $n$ equals the number of family relationship pairs) are generated. Third, a column of random

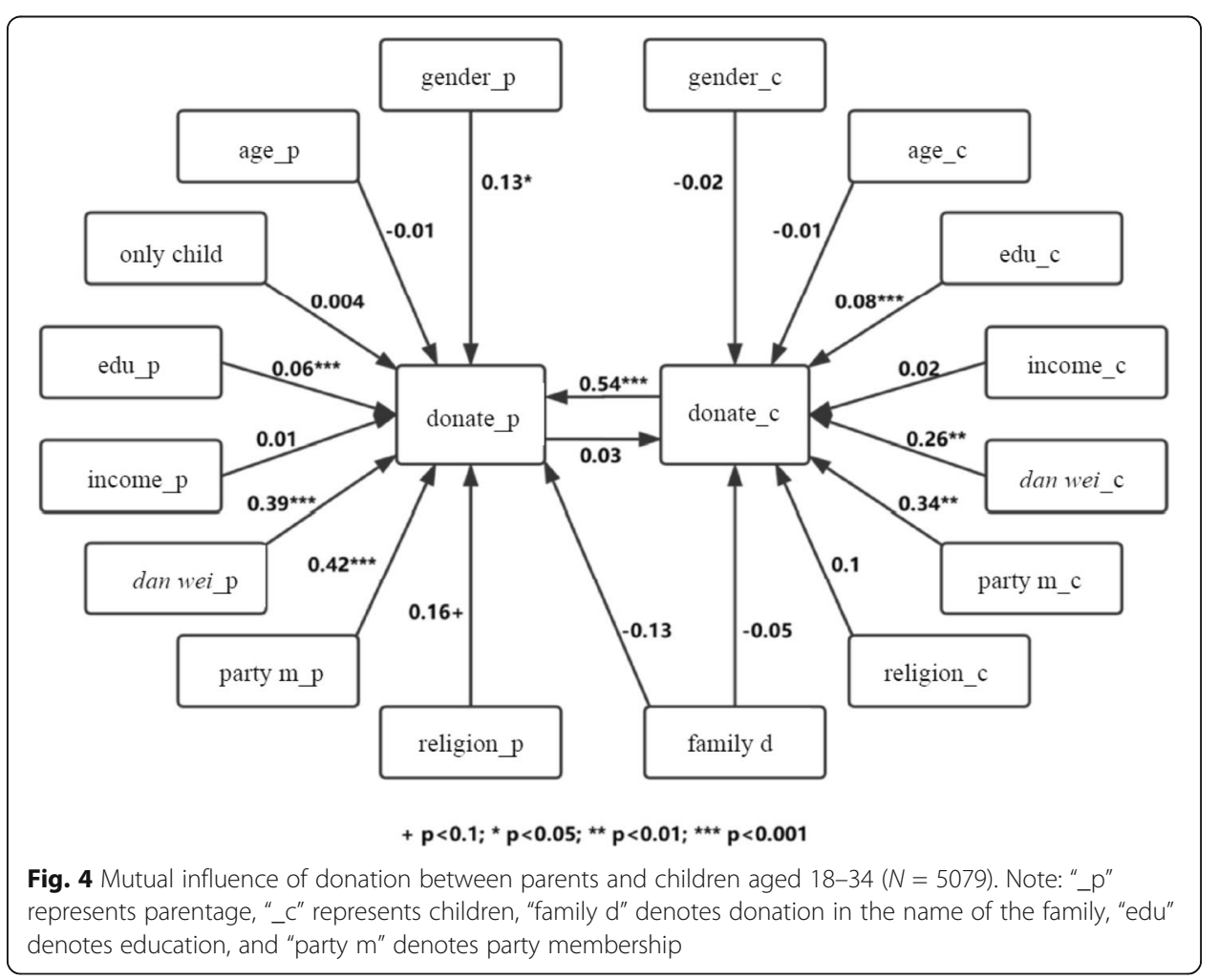


numbers are generated in the dataset, and the values of the random numbers are 1, 2, $3 \ldots, n$ (n equals the number of family relationship pairs). Fourth, the cases in which the sequence number of the relationship pair is equal to one of the random numbers are selected in each data set to form a new sample, and ten new samples (which exclude random families with only one relationship pair) are collected. Fifth, the ten new samples are combined. In the final sample, each family has only one pair of parent-child relationships, and 2730 parent-child relationship pairs are obtained.

The results of the robustness test are presented in Fig. 5. For the random sample selected from the families with multiple parent-child relationship pairs, the parents and children's donation participations still affect each other, and the influence of the children on the parents is significantly stronger than that of the parents on the children. This is consistent with the results that were obtained based on the overall sample. Moreover, the results demonstrate a satisfactory fit of the model (see Table 2). This supports the robustness of the analysis results and the reliability of the conclusion.

\section{Conclusions and discussion}

\section{Research findings}

The reasons for individual participation in charitable donations have received substantial attention in China in recent years. However, there is little discussion about the influence of family on charitable behavior. The main reason is that most of the studies that were undertaken in the Western context suppose that individual charitable donation is influenced primarily by individual factors, social organizations, and religious culture, while most of the domestic studies remain in the primary stage of applying the

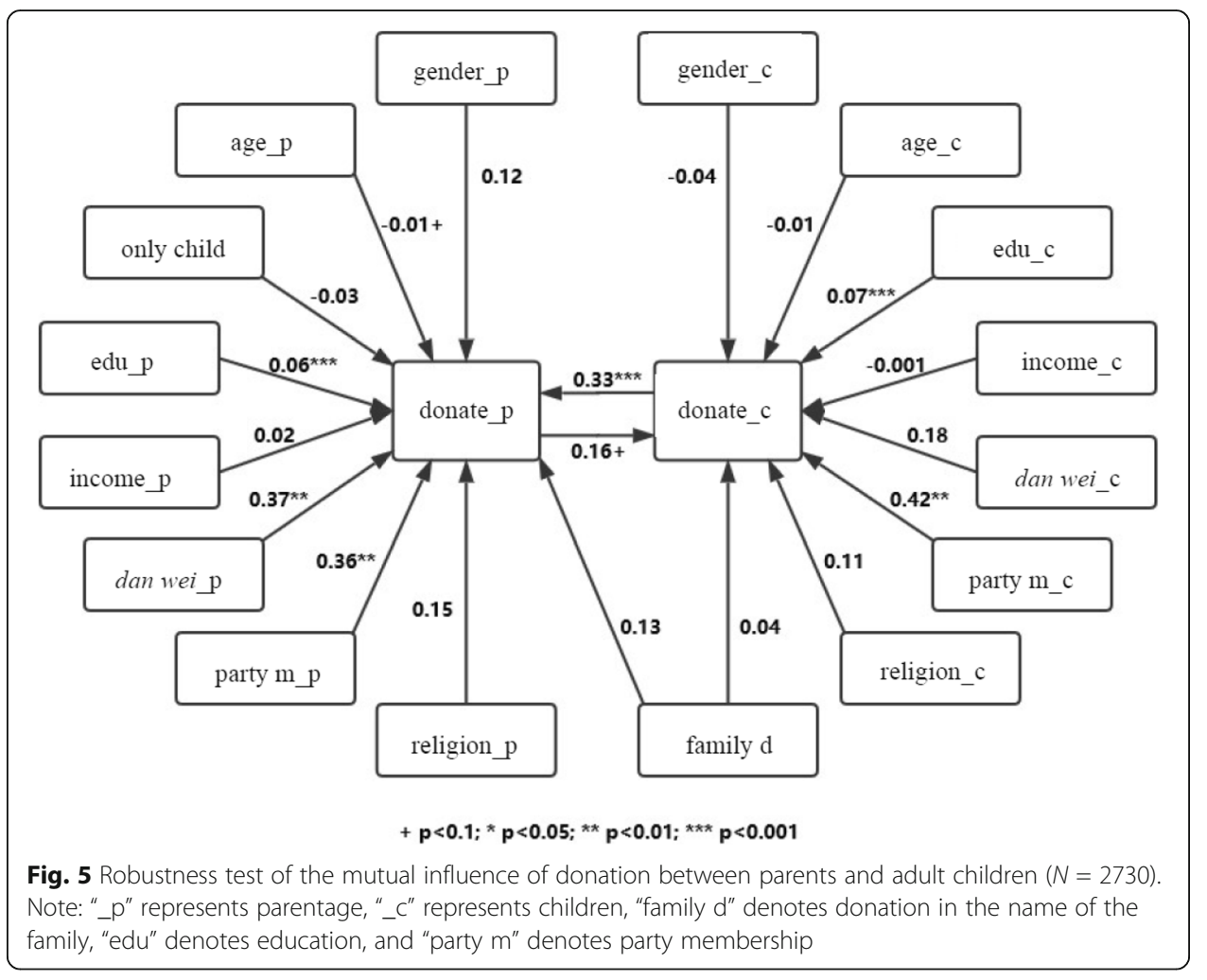


Western theoretical framework to the Chinese local context. Given the limitations of these previous studies, this study examines the intergenerational effect of a charitable donation from the perspective of the vertical family relationship based on the social structure, traditional culture, and philanthropic environment of China.

First, this study finds that the parents' participation in charitable donation has a significant positive impact on the children's participation in a charitable donation. As discussed above, the downward "inheritance" of charitable behavior proceeds through the process of socialization and the transfer of social and economic resources within the family. This is in line with previous research findings in the Western context. It indicates that in both China and Western countries, intergenerational transmission of philanthropy inside the family occurs. The continuity of family charitable behavior depends partly on the elders' role model and their material and spiritual support. This study further shows that the impact of parents' charitable donation on children persists into adulthood, namely, in addition to minor children easily learning their parents' attitudes and behaviors of philanthropy in the process of socialization, the adult children' charitable behavior remains influenced by their parents' charitable behavior. This reflects the traditional culture of "familism" in Chinese society. In contrast to the "emotion-oriented" intergenerational relationships in Western developed countries, Chinese children still functionally depend on their parents when they are adults (Shi 2016). This highlights the special significance of family to Chinese people. Family and family members have always had an important influence in all stages of individual life.

More importantly, in Chinese families, the intergenerational influence of charitable donation is bidirectional: it includes not only downward "inheritance" from the parents but also upward influence from the children. This corresponds to the phenomenon of "cultural feedback." According to (Zhou 2015:110), "cultural feedback has become an unprecedented experience of reshaping intergenerational relations for almost all Chinese families since the reform and opening-up in 1978." The reform caused the whole society to change rapidly in a very short period, thereby leading to substantial discrepancies of material and spiritual lives between the generations who were born before versus after 1978. Hence, the "subversion" of the traditional parent-child relationship in China is more thorough than in other countries and causes the phenomenon of "cultural feedback" to occur on a large scale in contemporary Chinese society (Zhou 2011). The phenomenon of "intergenerational feedback" in charitable donations shows that the intergenerational relationship is an important carrier of the spread of charitable behavior in the family. The analysis of family charitable behavior cannot ignore the special intergenerational relationship of Chinese society. To effectively cultivate a family culture of philanthropy and promote social participation of philanthropic activities, it is necessary to identify the mechanism by which charitable behavior is transferred in the family and utilize the downward force of "inheritance" and the upward force of "feedback."

Based on Zhou's concept of "intergenerational feedback," we further compare the force of feedback and the force of inheritance of charitable donation. The results demonstrate that as for charitable donation, especially in families with children born in the 1980s or the 1990s, the upward influence of children is stronger than the downward influence of parents. This is a more profound reflection of Chinese characteristics. First, it is related to the development of the philanthropic environment in China. The 
philanthropic environment in China began to improve in the 1980s. The scientific and technological revolution and the popularity of computers and mass media have rendered the modern concept of philanthropy profoundly influential among the post1980s and 1990s generation. The post-1960s and 1970s generation, who experienced the stagnation of China's philanthropy, have lost their advantages and authority in the field of discourse power of modern philanthropy. Second, the intergenerational relationship, shaped by China's family planning policy, is also an important source of children's discourse power. The family planning policy has increased the number of onechild families. In such families, children are so precious that the elders devote their emotion, energy, and resources to the only child and pay more attention to the offspring (Hao and Feng 1998). As a direct result, the offspring gradually replace their parents and become the dominant party in the intergenerational relationship interaction (Cai 2015), which strengthens the effect of reverse socialization. Moreover, due to a policy that advocates "controlling the quantity" and "improving the quality" in child rearing, children are valued because they are the hope of the family, while the elderly are often regarded as a burden due to their aging. Even if the children maintained the virtue of filial piety, when the resources were limited, "respect for the elderly" gives way to "care for the youth." The intergenerational relationship gradually changes from the "care-support" feedback mode (Fei 1983) to the "relay-feedback" mode (Yang 2017). Therefore, the family intergenerational relationship has changed from respecting the elderly to caring for the youth, and the upward parental relationship has gradually weakened in family life. Accordingly, the downward parental relationship plays an increasingly important role, and this trend is also embodied in the intergenerational effect of charitable donation. This provides young people who have received the influence of advanced philanthropy culture and ideas with substantial advantages in shaping the spirit of modern philanthropy in China.

\section{Implication and prospects}

To develop a theory of Chinese philanthropy, we must consider the "differential pattern" social structure and Confucianism as the kernel. Previous academic discussions have regarded Chinese familism as an obstacle to modern philanthropy, but the author believes that the family has strong potential for inspiring individual charitable behavior. In China, the family is always the basic unit of social life. Although substantial changes have been occurring in the Chinese social, economic, and cultural environments for thousands of years, the family retains its significant influence on various aspects of social life and philanthropy development. Confucianism emphasizes inheritance. The inheritance of philanthropy culture from parents to children and from the older generation to the younger generation is the transmission of the traditional Chinese concept of "benevolence." In addition, due to the "differential pattern" social structure, the roles of the family and family members in Chinese individual life are too significant to be surpassed by other social relations. Therefore, the attitudes and behaviors of family members play an irreplaceable role in the decision-making and diffusion of individual charitable behavior.

Hence, the family is an important social institution through which the tradition of philanthropy spreads, and the intergenerational relationship is an important carrier for 
the inheritance and feedback of philanthropic culture. Therefore, in the social context of China, the charitable behavior of family members is a factor that cannot be ignored when investigating the causes of individual participation in charitable donations. Scholars have concluded that the traditional Chinese philanthropic practice has always been characterized by a "strong state and weak society," and the concept and scope of individual charitable activities are limited, with remarkable particularity (Han and Zheng 2014). In the modern sense, philanthropy emphasizes the characteristics of nondifferential order, universality, and public welfare. This is a new concept for transforming Chinese society and a challenge for the development of Chinese philanthropy.

Suppose an individual's charitable behavior is regarded as a manifestation at the micro-level of philanthropy culture in the whole society. In that case, the strong "intergenerational feedback" effect of charitable behavior demonstrates that the traditional top-down inheritance mode of philanthropy culture changes to the bidirectional or even bottom-up transmission mode of philanthropy culture in modern society. For the transforming Chinese society, children have obtained greater discourse power in shaping family philanthropy culture. Against the background of more interactions between Chinese and Western philanthropy cultures and more exposure of the younger generation to the modern philanthropy concept, it would be substantially helpful for China to complete the modernization of philanthropy via the transmission of modern charity spirit and practice through "cultural feedback." This is not only the result of reform and opening-up but also the social concomitant of reform and opening-up over the past 40 years. "Cultural feedback" can promote symbiosis and harmony among the generations through mutual tolerance of multi-intergenerational culture and differences in the dramatic social transformation (Zhou 2015). The feedback effect of philanthropy can facilitate the joint growth of two generations, promote the communication and integration of traditional and modern philanthropy culture, and advance the new prosperity of Chinese philanthropy.

These results have critical implications for the mobilization of a charitable donation in China. To encourage individual charitable behavior, we need to locate the family as the core position of the incentive system. The transmission effect of charitable behavior via intergenerational relationships should be emphasized to utilize the family's incentive role. The primary direction and conditions of the transmission of charitable behavior in the family should be valued to improve the effect and refinement of mobilization strategies. The upward intergenerational transmission effect of charitable donation is stronger than the downward transmission effect. This not only supports the core position of downward intergenerational relations in Chinese families but also reflects the profound influence of the rise and development of philanthropy on the children, which leads to the powerful "cultural feedback" effect of the children. Therefore, in the development of philanthropy, we should strengthen the children's mobilization in the family and consider the young people's capacity for accepting new knowledge and their ability to use electronic products and high technology. We should encourage young people to help the elders in their families comprehend the concepts of philanthropy and to learn charity tools to spread the spirit of philanthropy.

Regarding the negative impact of familism on philanthropy in China, scholars suggest that the development of philanthropy must rely on the administrative power and the joint efforts of enterprises and individuals, which do not conform to the logic of 
"familism" (Gao and Wang 2011). This study examines the family's role in the development of China's philanthropy from a new perspective. The unique social structure is a vital element in the development of philanthropy in China. Since the influence of the "familism" culture on the public has been deeply rooted, the strategy of simply avoiding the influence of family and designing incentive measures for charity participation with non-family logic will not be effective in the long term. Instead, we must deeply and comprehensively examine the significance of family to philanthropy and proactively explore the role of the family in encouraging individual charitable behavior. As this study suggests, the transmission of charitable behavior and culture among family members can effectively promote individual charitable donation, the spread of family charitable behavior, and the cultivation of philanthropy culture in the broader society.

In addition, the results of this study emphasize the significance of charity in maintaining family relations. Just as "cultural feedback" has facilitated the construction of a convenient and clear bridge for generations to move toward symbiosis and harmony, the feedback effect of charitable behavior can also promote intergenerational harmony. Charity spreads the spirit of love and altruism. "Knowing the good" and "practicing the good" in philanthropic participation not only contribute to social harmony but also help reduce family conflicts. Moreover, new forms of charitable participation that involve families, such as the promotion of "parental philanthropy," have caused "individualized" charitable participation to develop into "family-oriented" charitable participation and have changed the "on-site participation" mode into the "interactive experience" mode. Charity not only provides a platform for children to participate in family interaction but also offers opportunities for parents to conduct family education and cultivate close parent-child relationships. It is reasonable to suggest that the intergenerational relationship of family members is not only the premise but also the result of family philanthropy.

Therefore, as an important agent in shaping charity, charitable organizations should focus on the intergenerational family relationship and work to embed the philanthropic spirit into the family culture. The credibility, organizational capacity, mobilization capacity, and staff communication ability of charitable organizations will affect participants' scale and composition and affect the development potential of family philanthropy. An unsuitable development strategy will result in the loss of donors and the stagnation of philanthropy. Charitable organizations that can successfully engage in family education and parent-child interaction can increase donors' loyalty over the long term. The mutual reinforcement between philanthropy culture and family involvement can promote the prosperity of philanthropy. Therefore, for charitable organizations, the family's intergenerational relationship is critical for understanding the status and possible changes in charitable behavior. Family culture and intergenerational relations in Chinese society have their own characteristics, and they serve as important codes for interpreting the complexity and diversity of philanthropy in China.

This exploratory study regards the intergenerational effect on charitable donation as the breakthrough point for promoting indigenous studies and the theoretical innovation of philanthropy in Chinese society. Based on a large-scale national survey in China, this study also generated family member pair relationships associated with charitable behavior for the first time, thereby providing data for further research. 
However, this study has several limitations: First, this study only examines whether individuals participate in charitable donation or not and does not consider the heterogeneity of donation behavior, e.g., in terms of the amount and type of charitable donation. This is mainly because the large-scale national survey does not include detailed data on individual donations, and several other surveys on the amounts of individual charitable donations suffer from significant missing data, which affects the validity of the analysis results. Therefore, this study failed to subdivide charitable donations. Nevertheless, the objective of this study has been realized. Second, this study only considers family members who live together and does not cover non-coresident family members. Future studies should identify the intergenerational effect on charitable donation by including non-coresident family members based on more comprehensive data. Finally, due to the limitations of the data and material, although this study outlines the path of intergenerational influence on donation based on a literature review, it considers only the intergenerational effect and not the mechanism of this effect. In the future, more targeted and detailed data can be used to fill in this gap.

Future studies can also further explore the gender roles in the intergenerational transmission of charitable donation, such as by comparing the roles and influences of fathers and mothers in the intergenerational transmission of charitable donation and refining the dynamic mechanism in the process of socialization regarding charitable behavior. Similarly, we also suggest comparing the influences of sons and daughters on the intergenerational feedback of charitable donation under various marriage conditions and examining the marriage effect and gender roles in cultural feedback. Finally, due to the drastic social transformation and the various development stages of Chinese philanthropy, the influence of the family on individual charitable behavior varies among periods and regions, and the most substantial differences are between urban and rural areas and among diverse generations. Further exploration of this phenomenon would enrich the relevant theories of philanthropy research and would be of substantial theoretical and practical significance for expanding the relevant research on China's social transformation.

Acknowledgments

N/A

Authors' contributions

Yongjiao Yang designed the study and conducted research, Yuting Shi contributed in theory construction and data cleansing, and Dong Zhang contributed in the data analysis and modeling. The authors read and approved the final manuscript.

Funding

This study was funded by the National Social Science Fund of China (NSSFC) (17CSH061)

Availability of data and materials

We based our study on data, publicly available of the China Labor-force Dynamic Survey (CLDS, 2014).

Competing interests

The authors declare that they have no conflict of interest.

${ }^{1}$ School of Public Affairs, Chongqing University, No.174 Shazhengjie, Shapingba, Chongqing 400044, China. ${ }^{2}$ School of Sociology and Anthropology, Center of Urban Study, Sun Yat-sen University, Guangzhou, China. ${ }^{3}$ Western Research Base of Sociology, Chongqing Technology and Business University, Chongqing, China. 
Received: 27 July 2020 Accepted: 29 October 2020

\section{Published online: 17 December 2020}

\section{References}

Acock, A. 1984. Parents and their children: The study of intergenerational influence. Sociology and Social Research 68 (2): $151-$ 171.

Andreoni, J., and L. Vesterlund. 2001. Which is the fair sex? Gender differences in altruism. Quarterly Journal of Economics 116 (1): 293-312.

Bekkers, R., and N. De Graaf. 2006. Education and prosocial behavior. Working paper. Utrecht: Department of Sociology / ICS Utrecht University.

Bekkers, R., and P. Wiepking. 2010. A literature review of empirical studies of philanthropy. Nonprofit and Voluntary Sector Quarterly 40 (5): 924-973.

Bénabou, R., and J. Tirole. 2006. Incentives and prosocial behavior. American Economic Review 96 (5): 1652-1678.

Bengtson, V.L. 1975. Generation and family effects in value socialization. American Sociological Review 40 (3): 358-371.

Bi, X., J. Jin., M. Ma, and J. He . 2010. The reach of Danwei mobilization: An analysis on urban residents' charitable giving to project Hope. Sociological Studies 6: 149-177.

Cai, J. 2015. The origin, theme and development trend of intergenerational relations: A literature review. China Youth Study 11: $38-42$.

Charity Aid Foundation. 2015. Word giving index 2015: A global view of giving trends. Kent: Charity Aid Foundation

Chen, G. 2011. Summary of Chinese legal history. Beijing: The Commercial Press.

Chi, L., and Z. Xin. 2013. Intermediary mechanism of trust intergenerational transmission: A conceptual model. Journal of Capital Normal University (Social Sciences Edition) 1: 140-147.

Deng, Z., and R. Xu. 2001. Family sociology. Beijing: China Social Sciences Press.

Eisenberg, N. 1990. Prosocial development in early and mid-adolescence. In From childhood to adolescence: A transitional period, ed. R. Montemayor, Gerald R. Adams, and Thomas P. Gullota, 240-268. Newbury Park: Sage.

Eisenberg, N., and R.A. Fabes. 1998. Prosocial development, consistency and development of prosocial dispositions. In Handbook of child psychology: Social, emotional, and personality development (Vol.3), ed. N. Eisenberg and W. Damon, 701-778. New York: Wiley.

Featherman, D.L., and R.M. Hauser. 1978. Opportunity and change. New York: Academic.

Fei, X. 1983. Support for the elderly in the change of family structure: On the changes of Chinese family structure. Journal of Peking University (Humanities and Social Sciences) 3: 7-16.

Fei, X. 1998. From the soil, fertility system. Beijing: Peking University Press.

Fukuyama, F. 2001. Trust: The social virtues and the creation of prosperity, Peng Zhihua translated. Hainan: Hainan Press.

Gao, Z., and J. Wang. 2011. Family-oriented concept: The bottleneck of Chinese public welfare. Journal of Social Work 8: 8587.

Glass, J., V.L. Bengtson, and C. Dunham. 1986. Attitude similarity in three-generation families: Socialization, status inheritance, or reciprocal influence? American Sociological Review 51 (5): 685-698.

Han, L. and G. Zheng. 2014. A comparative study of Chinese and Western charitable culture resources. Journal of Nanchang University (Humanities and Social Sciences) 1: 104-109.

Hao, Y., and X. Feng. 1998. Investigation and analysis on the characteristics of only child families in urban middle schools. Fujian Tribune ( A Economics \& Sociology Monthly) 3: 52-54.

Hochman, H.M., and J.D. Rodgers. 1977. The optimal tax treatment of charitable contributions. National Tax Journal 30 (1): 1-17.

Hodgkinson, V.A., and M.S. Weitzman. 1992. Giving and volunteering in the United States: Findings from a National Survey. Washington, DC: The Independent Sector.

Huang, J. 2008. The origin comparison and implication of charity culture between China and the west. Tianfu New Idea 3 : $107-110$.

Hu, R., and S. Shen. 2013. Social capital and individual donation in rural China. Journal of Public Administration 5: 60-75.

Liang, S. 2005. The substance of Chinese culture. Shanghai: Shanghai Renmin Press.

Lily Family School of Philanthropy. 2016. A tradition of giving: New research on giving and volunteering within families Indiana University - Purdue University Indianapolis (IUPUI).

Lin, N. 1986. The next step in the Sinicization of sociology. Sociological Studies 1: 89-96.

Liu, F., and W. Lu. 2013. Influence of social economical status upon charitable donation behavior. Journal of Beijing Normal University (Social Sciences) 3: 113-120.

Ma, R. 2007. The differential mode of association: Understanding of traditional Chinese social structure and the behaviors of the Chinese people. Journal of Peking University (Philosophy and Social Sciences) 2: 131-142.

Ma, C., J. Shi., Y. Li., Z. Wang., and C. Tang. 2011. Family change in urban areas of China: Main trends and latest findings. Sociological Studies 2: 182-216.

Mead, M. 1987. Culture and commitment: A study of the generation gap, Xiaohong Zhou and Yi Zhou translated. Shijiazhuang: Hebei Renmin Press.

Meer, J. 2011. Brother, can you spare a dime? Peer pressure in charitable solicitation. Journal of Public Economics 95 (7-8): 363-371.

Moen, P., M.A. Erickson, and D. Dempster-McClain. 1997. Their mother's daughters? The intergenerational transmission of gender attitudes in a world of changing roles. Journal of Marriage and the Family 59 (2): 281-293.

Mustillo, S., J. Wilson, and S.M. Lynch. 2004. Legacy volunteering: A test of two theories of intergenerational transmission. Journal of Marriage and the Family 66 (2): 530-541.

Pan, Y. and N, Lin. 1992. Vertical family relationship in China and its impact on society. Sociological Studies 6: 73-80.

Paxton, P.M., J. Hipp, and S. Marguat-Pyatt. 2016. Non recursive model: Endogeneity, reciprocal relation and feedback loop, fan Xinguang translated. Shanghai: Truth \& Wisdom Press.

Shah, D.V., M. Schmierbach, J. Hawkins, R. Espino, and J. Donavan. 2002. Non recursive models of internet use and community engagement questioning whether time spent online erodes social capital. Journalism and Mass Communication Quarterly 79 (4): 964-987.

Shen, Y. 2007. Guanxi, Renqing and Mianzi: The everyday practice of Ren, Yi, and Li. Open Times 4: 90-106. 
Shi, J. 2016. The evolvement of family intergenerational relationship in transition: Mechanism, logic and tension. Sociological Studies 6: 191-213.

Tian, C. 2009. A review of studies on family intergenerational relations. Tian Fu New Idea 1: 108-112.

Vesterlund, L. 2006. Why do people give? In Nonprofit sector: A research handbook, ed. R. Steinberg and W.W. Powell, 2nd ed. New Haven: Yale Press.

Wang, L., and E. Graddy. 2008. Social capital, volunteering and charitable giving. Voluntas: International Journal of Voluntary and Nonprofit Organizations 19 (1): 23-42.

Wang, Y. 2013. An analysis of the changes in China's urban and rural family structures: Based on 2010 census data. Social Sciences in China 12: 60-77.

Wang, N. 2017. Indigenization of sociology in China: Debates, core challenges, and the way forward. Sociological Studies 5: 15-38.

Weber, M. 1995. Confucianism and Taoism, Wang Rongfen translated. Beijing: The Commercial Press.

Wen, X. 2014. The Confucian family-centered ethic and generational justice. Nanjing Journal of Social Sciences 11: 47-53.

Wilhelm, M.O., E. Brown, P.M. Rooney, and R. Steinberg. 2008. The intergenerational transmission of generosity. Journal of Public Economics 92 (10-11): 2146-2156.

Yan, Y. 2006. "Chaxu geju"and the notion of hierarchy in Chinese culture. Sociological Studies 4: 201-213.

Yang, F. 2009. The comparison between charity culture and Chinese charity. Shandong Social Sciences 1: 76-79.

Yang, S. 2011. The change of urban families in contemporary China and family cohesion. Journal of Peking University (Philosophy \& Social Sciences) 2: 150-158.

Yang, J. 2017. Fertility policy and family change in China. Open Times 3: 12-26.

Yao, J. 2012. "Temporary stem family": The transformation and strategy of family structure in cities. Youth Studies 3: 85-93.

Yu, Y. 2003. Modern interpretation of Chinese thought tradition. Nanjing: Jiangsu Renmin Press.

Zhang, J. 2010. Charisma, publicity, and China society. Chinese Journal of Sociology 5: 1-24.

Zhao, B. 2011. A study on the role of government in charitable donation motivation. Academics 10: 155-160.

Zhou, X. 1988. On the significance of feedback of youth culture in contemporary China. Youth Studies 11:22-26.

Zhou, X. 2000. The cultural feedback: Parental transmission in transforming society. Sociological Studies 2: 53-68.

Zhou, X. 2011. Cultural repayment of support and the intergenerational inheritance of artifact civilization. Social Sciences in China 6: 109-120

Zhou, Q., and Y. Lin. 2014. Inheritance and reconstruction: The history and reality of China charity development transformation. Qilu Journal 2: 82-87.

Zhou, X. 2015. From subversion and growth to symbiosis and harmony: Intergenerational influence and social significance of cultural feedback. Hebei Academic Journal 3: 104-110.

Zhu, J., and Y. Liu. 2017. An exploratory research on the scale and major factors of Chinese household donation: An analysis based on China labour force dynamics survey. Chinese Journal of Population Science 1: 47-58.

\section{Publisher's Note}

Springer Nature remains neutral with regard to jurisdictional claims in published maps and institutional affiliations.

\section{Submit your manuscript to a SpringerOpen ${ }^{\circ}$ journal and benefit from:}

- Convenient online submission

Rigorous peer review

- Open access: articles freely available online

- High visibility within the field

- Retaining the copyright to your article

Submit your next manuscript at $\boldsymbol{\nabla}$ springeropen.com 